\title{
ПРЕДИСЛОВИЕ К ПУБЛИКАЦИИ: ФРИДРИХ ВАЙСМАН «ЧТО ТАКОЕ ЛОГИЧЕСКИЙ АНАЛИЗ?»
}

\section{Я.В.Шрамко}

Фридрих Вайсман сыграл важную роль в истории Венского кружка, хотя его вряд ли можно отнести к «звездам первой величины», таким, например, как Рудольф Карнап или Отто Нейрат, революционные идеи которых сформировали основополагающие принципы логического позитивизма. Практически сразу же после того, как Мориц Шлик занял в 1922 году кафедру философии индуктивных наук Венского университета, Вайсман - сначала в качестве его студента, а затем и фактического научного ассистента - вошел в группу исследователей, на основе которой очень скоро сформировалось интеллектуальное движение, получившее название «Венский кружок». Роль Вайсмана, однако, далеко не исчерпывалась активным участием в организации работы семинара, которым руководил Шлик, но определялась, прежде всего, спецификой взаимоотношений членов кружка с Людвигом Витгенштейном, громко заявившем о себе публикацией в 1921 году «Логико-философского трактата».

Известно, какое большое значение придавали участники Шликовского семинара труду Витгенштейна, который Шлик даже охарактеризовал как «самое важное произведение философии нашего времени» ${ }^{1}$. В 1925-27 гг. на заседаниях кружка «Трактат» детально, буквально строчка за строчкой, изучался и обсуждался в стремлении использовать заложенные в нем идеи в качестве надежного основания для

${ }^{1}$ Schlick M. Vorrede, in: Waismann F. Logik, Sprache, Philosophie. - Stuttgart, 1976. - S. 20. 
развиваемой Венским кружком философской доктрины. В частности, это касалось задачи нахождения философских и математических оснований для новой (символической) логики, а также таких центральных для логического позитивизма принципов, как научный эмпиризм, верифицируемость научных утверждений и ограничение задач философии логическим анализом и прояснением научного языка ${ }^{2}$.

В 1927 году состоялось и личное знакомство Шлика с Витгенштейном. Последний, однако, отклонил приглашение принять непосредственное участие в заседаниях семинара и ограничился разрозненными, хотя и более-менее регулярными, встречами и беседами с некоторыми членами Венского кружка. В этих встречах неизменно участвовал и Вайсман, который, по просьбе Шлика, записывал содержание этих бесед, с тем чтобы позднее можно было осмыслить и обсудить затрагиваемые в них философские проблемы. Более того, в 1928 году по инициативе Шлика возник проект написания книги, соавторами которой должны были выступить Витгенштейн и Вайсман. Первоначально предполагалось, что в этой книге будут подробно представлены и разъяснены некоторые центральные идеи «Логико-философского трактата», с тем, чтобы сделать их более доступными для широкой философской аудитории. В ходе непосредственной работы над книгой Вайсман должен был записывать, систематизировать и обрабатывать содержание бесед Витгенштейна с ним и Шликом по указанным проблемам. Выход книги под названием «Логика, язык, философия» был

\footnotetext{
${ }^{2}$ Нужно сказать, что вопрос о том, насколько значительным было действительное воздействие Витгенштейна и его «Логико-философского трактата» на становление философской концепции Венского кружка (и было ли оно вообще), далек от однозначности. В литературе по этому поводу можно встретить диаметрально противоположные мнения - от безоговорочного признания важности для логического позитивизма «влиятельных импульсов», исходивших от Витгенштейна ( Kpaøm B. Венский кружок. - М. : Идея-Пресс, 2003. - С. 40), до полного отрицания какого бы то ни было влияния «Трактата» на «миропонимание и деятельность Венского кружка» (Назарова О.А. Логический позитивизм и «Трактат» Витгенштейна // Вопросы философии. - 2008. - №6. - С. 143-151). Вообще говоря, тема «Витгенштейн и Венский кружок» довольно обширна и многоаспектна. Однако в контексте данной небольшой заметки, для правильного понимания содержательной направленности философских работ и всей деятельности Вайсмана в довоенный период, важно не столько «объективное» значение идей Витгенштейна для философии Венского кружка, сколько каким оно виделось (пусть даже и в несколько преувеличенном свете) самим его представителям. Тут достаточно сослаться на программную статью Шлика «Поворот в философии» (см.: Журнал «Erkenntnis» («Познание»). Избранное. - М. : Издательский дом «Территория будущего», ИдеяПресс, 2007), где Шлик эксплицитно связывает указанный «решающий поворот» в первую очередь именно с «Логико-философским трактатом» Витгенштейна.
} 
анонсирован на 1931 год в качестве первого тома книжной серии «Труды по научному миропониманию».

Однако работа по реализации этого проекта с самого начала отклонилась от намеченного плана. В январе 1929 года Витгенштейн принял решение вернуться в Кембридж и продолжить там свои философские исследования и преподавательскую деятельность. С этого времени он мог быть в Вене лишь наездами. Тем не менее, контакты Вайсмана с Витгенштейном продолжались в виде переписки, а также во время посещений последним Вены. Вначале Вайсман был занят тем, что пытался в ясной и доступной форме изложить основные идеи «Логико-философского трактата» и консультировался с Витгенштейном на предмет точности и корректности своих формулировок. Но вскоре Витгенштейн пришел к мысли, что задуманная книга должна излагать не столько логико-философскую концепцию «Трактата», сколько новые философские идеи, к разработке которых он в это время приступил. Тут следует учитывать, что, начиная с 30-х годов, Витгенштейн подверг радикальному пересмотру многие положения «Трактата» и его отношение к собственным ранним идеям становится все более критическим. В результате, проект книги вначале претерпел существенную модификацию, а в конце 1934 года Витгенштейн и вовсе решил из него выйти, оставив, впрочем, за Шликом и Вайсманом право продолжить написание книги без его участия. После этого Вайсман работал над книгой самостоятельно и к 1937 году она в целом была готова. Однако попытки Вайсмана опубликовать свой труд в Австрии или Голландии не увенчались успехом из-за нестабильной политической обстановки и разгоревшейся вскоре Второй мировой войны и впервые он был издан уже после его смерти в английском переводе под названием «Принципы лингвистической философии» $(1965 \text { г. })^{3}$.

Несмотря на все трудности совместной работы с Витгенштейном, само интенсивное обсуждение широкого круга философских проблем и разрабатываемых им идей несомненно способствовало тому, чтобы Вайсман, проникшись этими идеями, стал, в конце концов, их адептом и фактически взял на себя функцию своего рода «официального проводника» этих идей среди членов Венского кружка ${ }^{4}$. Как отмечает из-

\footnotetext{
${ }^{3}$ Waismann F. The Principles of Linguistic Philosophy. - London, Macmillan; New York: St. Martin's Press, 1965.

4 Это, однако, не следует понимать так, будто Вайсман получил от Витгенштейна какой-то «карт бланш» на такого рода деятельность. Напротив, последний в письме Шлику даже жаловался на то, что, по его убеждению, Вайсман «совершенно неверно» излагает многие его идеи (см.: Backer G. (Ed.) The Voices of Wittgenstein: The
} 
вестный исследователь философии Витгенштейна и Венского кружка Брайан МакГиннесс, взаимоотношения с Витгенштейном «определяли жизнь Вайсмана в течение, по крайней мере, десяти лет. Он принимал любое положение, которое выдвигал [Витгенштейн] и был готов защищать на заседаниях кружка Шлика даже те из этих положений, которые (как казалось) защищать было невозможно» ${ }^{5}$. Иными словами, в довоенный период философская мысль Фридриха Вайсмана в значительной степени вращалась вокруг проблематики, задаваемой философскими идеями Людвига Витгенштейна. Именно под этим углом зрения следует рассматривать практически все работы, вышедшие из-под его пера в это время.

Типичной в этом отношении представляется статья «Что такое логический анализ?», в которой Вайсман, обобщая некоторые центральные положения теории значения «Логико-философского трактата», излагает и подробно разбирает критические замечания по поводу этой теории, выдвинутые Витгенштейном в более поздний период его философского развития. Впрочем, это вовсе не означает, что содержание статьи сводится к простому воспроизведению разрозненных идей Витгенштейна. Не говоря уже о том, что Вайсман, как обычно, стремится внести ясность и упорядоченность в запутанный конгломерат этих идей, он тщательно выстраивает собственную аргументацию в пользу такого понимания логического анализа, которое в некоторых важных аспектах существенно отклоняется от подходов, характерных для Витгенштейна. Таким образом, вполне можно утверждать, что данная статья представляет именно концепцию Вайсмана, хотя и находящуюся под значительным влиянием философии Витгенштейна.

Исходным пунктом статьи является фундаментальное положение логического позитивизма, согласно которому задача философии состо-

Vienna Circle Ludwig Wittgenstein and Friedrich Waismann. - London \& New York: Routledge, 2003. - Р. xxvi). В частности, недовольство Витгенштейна вызвали так называемые «Тезисы», написанные Вайсманом в 1931 г. по поручению Шлика, в которых он попытался резюмировать основные положения «Логико-философского трактата». Эти «Тезисы» широко обсуждались среди членов Венского кружка. Витгенштейн же усмотрел в них простое «перекраивание» тех «догматических положений» «Трактата», с которыми сам он был уже «не согласен» (см. там же). Оставляя в стороне вопрос, насколько обоснованными были упреки и подозрения Витгенштейна, отметим, что в изложении идей последнего Вайсман во-многом действовал «на свой страх и риск», что неоднократно вызывало напряжения в отношениях между ними, и в 1936 году привело к полному разрыву.

${ }^{5}$ McGuinness B.F. Waismann: the wandering scholar // McGuinness B.F. (Ed.) Friedrich Waismann-Causality and Logical Positivism (Vienna Circle Institute Yearbook Vol.15), 2011. - P. 10. 
ит не в установлении истинных утверждений о какой-то предметной области, а в прояснении таких предложений, устанавливаемых конкретными науками, и в этом смысле философия представляет собой не что иное, как «логический анализ наших мыслей». Таким образом, первостепенное значение для определения сущности философии приобретает вопрос о том, что должен представлять собой логический анализ как таковой.

Рассмотрение этого вопроса Вайсман начинает с изложения истинностно-функционального подхода к значениям языковых выражений, согласно которому значение сложного предложения представляет собой истинностную функцию от составляющих его простых предложений. В «Логико-философском трактате» принимается концепция, в соответствии с которой любое сложное предложение можно разбить на некоторые исходные, далее неразложимые сущности, своего рода «логические атомы» или «элементарные предложения». Эти последние должны быть полностью сводимы к чувственным данным и представлять собой так называемые «предложения восприятия», что в методологии Венского кружка получило название «протокольных предложений». Здесь фактически предполагается идеальный логический язык, удовлетворяющий некоторым довольно сильным требованиям, таким как возможность его полной формализации. Соответственно и для элементарных предложений такого языка должен выполняться ряд условий, в соответствии с которыми эти предложения: (1) являются совершенно простыми; (2) логически независимы друг от друга; (3) изоморфны тем или иным фактам действительности.

Далее Вайсман ставит вопрос о применимости такого подхода к реальным языкам, используемым в повседневной жизни и научных исследованиях, и спрашивает, существуют ли в нашем языке предложения, которые соответствовали бы требованиям, выдвигаемым к элементарным предложениям и можно ли вообще указать пример такого рода элементарного предложения. Тут следует отметить, что такая постановка вопроса - с упором на естественный язык - вполне в духе зрелого Витгенштейна. В ходе тщательного анализа указанной проблемы Вайсман приходит к выводу о невозможности разбиения предложений «действительного языка» на истинностные функции от неких изначально заданных элементарных предложений. Допущение такого разбиения совершенно не соответствовало бы «грамматическим правилам» употребления языковых выражений нашего языка. Под «грамматическими правилами» Вайсман, по сути, понимает логические правила (точнее, он говорит о «правилах логической грамматики»). 
Логический анализ, по мысли Вайсмана, как раз и представляет собой выявление логических правил употребления языковых выражений. При этом проблема обоснования логических правил решается Вайсманом в сугубо антиреалистском ключе, поскольку в качестве критерия адекватности того или иного правила он берет факт принятия этого правила носителями языка. Он подчеркивает, что языковые правила «никогда нельзя вывести из чего-нибудь более глубокого, доказать их или опровергнуть, разве что из других правил. Последний пункт, к которому ведет такого рода исследование, всегда представляет собой наше решение». Здесь явно просматривается крен в сторону конвенционализма, который также имеет глубокие корни в философии Венского кружка. Языковые выражения не имеют никакой раз и навсегда заданной «объективно существующей» логической формы. Такая форма существенным образом определяется принимаемыми логическими и грамматическими правилами, а также потребностями логического анализа определенного языка.

Таким образом, данная статья фиксирует важный этап в развитии различных подходов к теории значения языковых выражений, отражая сложный процесс перехода от предметной концепции значения, характерной для «Логико-философского трактата», к пониманию значения языковых выражений как их употребления, задекларированному позднее Витгенштейном в его «Философских исследованиях». Присущая Вайсману ясность и четкость в постановке и рассмотрении философских проблем, в полной мере проявились и в данной его работе, что делает ее образцовым произведением того философского направления, которое она представляет и поэтому эта статья заслуженно считается своего рода locus classicus аналитической философии ${ }^{6}$.

В завершение нельзя не сказать несколько слов о жизненном пути Фридриха Вайсмана, которого МакГиннесс в одной из своих недавних статей охарактеризовал как «странствующего ученого» ${ }^{7}$. Эта характеристика представляется не вполне удачной - Вайсман, конечно же, не относился к тому встречающемуся иногда типу ученых, которые, не имея собственного крова, кочуют от одного коллеги и товарища к другому, черпая вдохновение в постоянном интеллектуальном общении и совместном научном и философском творчестве (здесь сразу приходят

${ }^{6}$ Cм.: Buchholz K. Einleitung // Waismann F. Was ist logische Analyse?Hamburg: EVA, 2008. - S. 15.

${ }^{7}$ McGuinness B.F. Waismann: the wandering scholar // McGuinness B.F. (Ed.) Friedrich Waismann-Causality and Logical Positivism (Vienna Circle Institute Yearbook Vol.15), 2011. - P. 9. 
на ум украинский философ Григорий Сковорода и венгерский математик Пол Эрдеш).

Тем не менее, определенные основания для такой характеристики все же имеются. Вайсман родился в 1896 году в Вене, но поскольку его отец, будучи эмигрантом из Одессы, не имел австрийского гражданства, то и сам он считался в Австрии иностранцем. По этой причине семья Вайсмана должна была вносить повышенную плату за его обучение в средней школе, а позже и в университете. После окончания университета Вайсман решил не тратить время на написание диссертации, а вместо этого сразу же взялся за создание фундаментального труда по феноменологии пространства. Труд этот так никогда и не был закончен. Параллельно Вайсман вел за Шликом семинары, хотя, не имея научной степени, он не мог претендовать на место «официального» преподавателя в университете. Чтобы хоть немного поддержать Вайсмана в материальном плане, Шлик устроил его на должность факультетского библиотекаря, которую тот и занимал вплоть до трагической гибели Шлика в 1936 году. После смерти Шлика даже эта должность стала для Вайсмана недоступной и он был вынужден вовсе оставить университет. Правда перед этим ему все же удалось защитить диссертацию и получить степень доктора философии, благодаря поддержке Роберта Райнингера, который в 1912-1939 был председателем философского общества Венского университета.

Однако любая перспектива научной и преподавательской карьеры в Австрии была для Вайсмана закрыта, учитывая его национальную принадлежность и политическую обстановку тех лет. К счастью, в конце 1937 года Вайсману была предложена стипендия британского Совета поддержки ученых, благодаря которой он и его семья смогли выехать в Кембридж, где он занял временную (на один семестр) должность преподавателя. В это время Витгенштейна в Кембридже не было, но он вернулся весной 1938 года, что значительно осложнило пребывание там Вайсмана. Коллеги и студенты Витгенштейна стереотипным образом воспринимали Вайсмана не иначе как эпигона Витгенштейна, излагающего, к тому же, частично устаревшие идеи, которые сам Витгенштейн уже давно отбросил ${ }^{8}$. Те из английских кол-

\footnotetext{
${ }^{8}$ Опять-таки, мы оставляем в стороне вопрос, насколько обоснованным и справедливым было такое восприятие и какова роль самого Витгенштейна в формировании указанного стереотипа. Вообще, проблема взаимоотношений Витгенштейна и Вайсмана в период пребывания последнего в Кэмбридже имеет ярко выраженную морально-этическую окрашенность и далека от однозначности (см., напр. McGuinness B.F. Op. cit. - P. 12-14).
} 
лег, которые симпатизировали Вайсману, советовали ему переехать в Оксфорд, где он мог бы получить лучшие перспективы, и в 1940 году Вайсман так и поступил. Там ему была предоставлена постоянная позиция университетского преподавателя философии математики и философии науки. Именно в Оксфорде в полной мере раскрылся талант Вайсмана как преподавателя. Его лекции и доклады пользовались большим успехом и в целом его преподавательская и научная деятельность в Оксфорде оказала значительное влияние на процесс становления «философии обыденного языка», среди основателей которой выделяют Джона Остина и Гилберта Райла.

В последние годы Вайсман жил довольно замкнуто, хотя у него и был небольшой круг дружеского общения, в который входили, в частности Гилберт Райл и Исайя Берлин. За весь оксфордский период он опубликовал не более десятка статей, каждую из которых отличала глубина и основательность подхода к разрабатываемым проблемам. Некоторые из этих статей привлекли значительное внимание философской общественности, в особенности работа 1956 года «Как я понимаю философию». Вайсман скончался 4 ноября 1959 г. Среди его бумаг, кроме большого числа заметок и всевозможных записей на сугубо философские темы, было обнаружено также собрание стихотворений и афоризмов (на немецком языке), в которых он горько сетует на окружающую его английскую действительность.

Надійшла до редакчіӥ 10 травня 2015 р. 